Results: According to the results of the FACIT-F, the patients were identified: no fatigue (52-34 points) - $99(53.1 \%)$, the presence of fatigue (2133 and less points) $-68(36.3 \%)$ and severe fatigue (20 and less points) -20 $(10.6 \%)$. By patient with fatigue and severe fatigue significant worse in all activity indexes and PROs than in patients not experiencing fatigue $(p<0,001$ and $p<0,0001$ ), (Table 1). Similar results were demonstrated across all PSAID12 domains (Figure 1), especially the domains "Pain", "Skin problems", "Work and/or leisure activity", "Sleep disturbance", "Function capacity" and "Discomfort" $(p<0.0001)$

Conclusion: In patients with PSA fatigue affected significant and clinically considerable impairment of PsA activity and PROs.

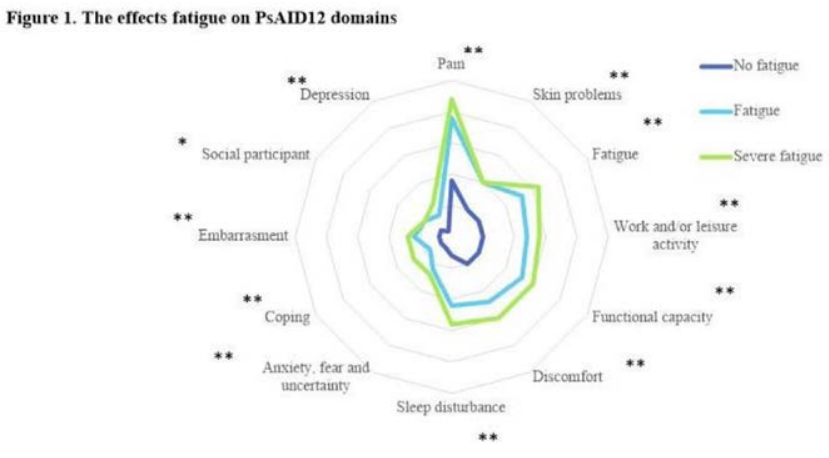

${ }^{*} p<0.01 ;{ }^{* *} p<0.0001$

Disclosure of Interests: None declared.

DOI: 10.1136/annrheumdis-2021-eular.3698

\section{AB0581 NAIL PSORIASIS AMONG PATIENTS WITH PSORIATIC ARTHRITIS IS MORE ASSOCIATED WITH THE SEVERITY OF SKIN PSORIASIS THAN WITH FEATURES OF SEVERE ARTHRITIS}

M. Haroon ${ }^{1}$, S. Farrukh ${ }^{2}$, S. Batool ${ }^{1}$, S. Asif ${ }^{1}$, O. Fitzgerald ${ }^{3} .{ }^{1}$ Fatima Memorial Hospital \& FMH College of Medicine and Dentistry, Department of Rheumatology, Lahore, Pakistan; ${ }^{2}$ University Hospital Kerry, Department of Rheumatology, Tralee, Ireland; ${ }^{3}$ University College Dublin, Conway Institute for Biomolecular Research, Dublin, Ireland

Background: Nail disease is an important feature of psoriasis arthritis (PsA), and has been recognised as one of the 6 important clinical domains by GRAPPA. Little is known about how patients with PsA and nail disease compare to patients without nail disease. Nail disease has been found to associate with severe PsA. Objectives: The objective of this study was to examine the association of nail disease with patient demographics and features of active psoriasis and PsA. Methods: For this cross-sectional study, data from 3 PsA cohorts was studied (St Vincent's University Hospital Dublin, Ireland; University Hospital Kerry, Ireland; and Fatima Memorial Hospital Lahore, Pakistan). Following informed consent, patients underwent detailed skin and rheumatologic assessments including disease activity measures. Since a large number of patients were in clinical remission at the time of assessment, we made 2 documentations of reversible clinical variables (e.g., current skin scores (PASI), current nail disease, current tender and swollen joint counts, current enthesitis, current dactylitis) at the time of study entry and, through extensive medical record review, we identified patient's maximum skin and joints disease activity scores ever documented, e.g., maximum skin scores (PASI max), TJC max, SJC max, nail disease ever, dactylitis ever, enthesitis ever. Nail disease was stratified by the presence or absence of nail psoriasis.

Results: Data on 476 PsA patients was assessed (age 53.8 \pm 10.8 , PsA duration $13.9 \pm 10$ years, BMI 29 \pm 5 ; current PASI $2.5 \pm 3.2$, current TJC $1.8 \pm 2.6$ years, current SJC $1.4 \pm 2.2$ years; $37 \%$ of the cohort had enthesitis ever, $46 \%$ had dactylitis ever, $30.7 \%$ had current dactylitis, and $28 \%$ with current enthesitis). $63.4 \%(n=302)$ of the cohort ever had nail disease, and $45.4 \%(n=216)$ had current nail disease at the time of assessment. On univariate analysis, significant or marginally significant statistical association of current nail disease was noted with current PASI $(p<0.001)$, enthesitis ever $(p=0.004)$, current enthesitis $(p=0.11)$, dactylitis ever $(p=0.027)$, current dactylitis $(p=0.07)$, MDA not achieved $(p<0.001)$, current SJC $(p=0.08)$, and current TJC $(p=0.32)$; however, no statistical association was noted with age, gender, disease duration, smoking status, low education status. The following variables were included in multiple stepwise regression analysis: current PASI, current enthesitis, current dactylitis, current TJC, current SJC, MDA not achieved, and low education status; a significant association of current nail disease was noted with current PASI (OR 2.2, CI
1.83-2.54, $\mathrm{p}<0.001$ ) with a borderline association of current dactylitis (OR 1.6, $\mathrm{Cl}$ $0.94-2.58, \mathrm{p}=0.083$ ). When we used nail disease ever as a dependent variable in the multiple regression model using covariates of PASI max, TJC max, SJC max, dactylitis ever, enthesitis ever, MDA not achieved and low education status, a significant association of nail disease ever was noted with PASI max (OR 1.09, Cl 1.01-1.17, $p=0.01$ ), TJC max (OR 1.08, Cl 1.02-1.14, $\mathrm{p}=0.005$ ) and borderline association with dactylitis ever (OR 1.74, Cl 0.96-3.15, $\mathrm{p}=0.067$ )

Conclusion: The presence of nail disease among patients with PsA is significantly associated with severity of skin psoriasis with only borderline associations with measures of active musculoskeletal involvement.

Disclosure of Interests: Muhammad Haroon Speakers bureau: Roche, Novartis, Grant/research support from: Abbvie, Pfizer, shehla farrukh: None declared. Shabnam Batool: None declared., Sadia Asif: None declared., Oliver FitzGerald Speakers bureau: Abbvie, Janssen, Pfizer, Consultant of: BMS, Celgene, Eli Lilly, Janssen, Pfizer, Grant/research support from: Abbvie, BMS, Eli Lilly, Novartis, Pfizer.

DOI: 10.1136/annrheumdis-2021-eular.3848

\section{Osteoarthritis}

\section{$\mathrm{AB} 0582$ \\ KNEE OSTEOARTHRITIS PHENOTYPES STRATIFICATION}

K. Korochina ${ }^{1}$, T. Chernysheva ${ }^{1}$, I. Korochina ${ }^{2}$, V. Klementeva ${ }^{1}$, G. Kuznetsov ${ }^{1}$ ${ }^{1}$ Orenburg State Medical University, The Department of Internal Diseases, Orenburg, Russian Federation; ${ }^{2}$ Orenburg State Medical University, The Department of Polyclinic Therapy, Orenburg, Russian Federation

Background: Osteoarthritis $(\mathrm{OA})$ relevance is determined by its record prevalence with progredient growth throughout the world [1]. Clinical and pathogenic heterogeneity of disease actualizes problem of its stratification [2]. Lack of unified understanding of $\mathrm{OA}$ and its phenotype determination results in incredible number of attempts to group OA, using of different classification criteria in last decade.

Objectives: To analyze and systematize available OA classifications, proposals and phenotypes, to highlight the most promising of them.

Methods: We studied publications from MEDLINE / PubMed and Google Scholar databases found by the keywords "osteoarthritis", "phenotypes", "subphenotypes" "classification", "subtypes", "subsets", "subgroups", "subpopulations", "profiles" and "endotypes" in various combinations in English and Russian. We did not set a time frame, but aimed to include as many different methods as possible in order to reflect evolution of scientists' views on structuring of this disease.

Results: A total of 55 OA grouping methods were covered so that OA was structured by different determinants into 6 big boxes.

\section{STRATIFICATION OF KNEE OSTEOARTHRITIS CLASSIFICATIONS}

\begin{tabular}{|c|c|c|}
\hline ETIOLOGICAL & \multirow{8}{*}{$\begin{array}{c}\text { CLINICAL: } \\
\text { CLINICAL AND } \\
\text { PATHOGENIC } \\
\text { CLINICAL AND } \\
\text { STRUCTURAL } \\
\text { BY COMORBIDITY } \\
\text { BY GAIT } \\
\text { DISORDER } \\
\text { BY DISABILITY } \\
\text { BY PAIN } \\
\text { PSYCHO-PAIN }\end{array}$} & \multirow{3}{*}{$\begin{array}{c}\text { STRUCTURAL: } \\
\text { RADIOLOGIC } \\
\text { MRI }\end{array}$} \\
\hline GENETIC & & \\
\hline LABORATORY & & \\
\hline METABOLOMIC & & ANATOMICAL \\
\hline & & $\begin{array}{c}\text { HISTOPATHOLOGIC } \\
\text { AL }\end{array}$ \\
\hline TRAJECTORIES: & & BY DAMAGED JOINT \\
\hline $\begin{array}{c}\text { PAIN } \\
\text { STRUCTURAL }\end{array}$ & & $\begin{array}{l}\text { BY LOCATION IN } \\
\text { JOINT }\end{array}$ \\
\hline $\begin{array}{l}\text { BY ACTIVITY } \\
\text { LIMITATIONS }\end{array}$ & & \\
\hline
\end{tabular}

First OA classifications were characterized by complex etiopathogenetic approach, while subsequent studies differed in joint-mediated approach, and the knee joint was undisputed "champion" in this "race". One of the first attempts to group OA was division into primary, or idiopathic, and secondary, due to known causes. It is now obvious that it is becoming obsolete, and criteria for OA primacy are difficult to determining. Genomic highly specialized studies based on isolation of "favorable" and "unfavorable" genes develops prerequisites to genetic OA classifying. Clinical variants occupy central place as they are the most fully consistent with modern phenotype conception [3], considerating as subtypes of disease shared by underlying pathobiological and pain mechanisms and their structural and functional consequences. Trajectories of OA progression are distinguished by longitudinal design, that is, the determinants for grouping here are disease characteristics in dynamics. The ances tor of structural OA trajectories can be considered Kellgren-Lawrence grades; 
subsequent studies identified complex of clinical, laboratory and morphological factors contributing to development of trajectories. Structural OA variants are diverse depending on visualization methods, and many of them can be naturally considered phenotypes, since they drive certain clinical OA manifestations. Morphological changes were described at macro- and microscopic levels; it is interesting to note the absence of histopathological norm in patients without OA. Laboratory profiles of patients are determined by content of systemic (serum, urinary) or local, "proximal" (in synovial fluid) biomarkers, which seem to be more precise. Metabolomic analysis is perspective new direction of laboratory studies based on joint metabolic products identification in the synovial fluid. New trend in OA research is molecular phenotyping. The specific molecular pathway explaining observed phenotype properties is called "endotype." Endotype is related to certain pathobiological scenario, and laboratory markers are potentially effective for its diagnosis.

Conclusion: Thus, a large amount of accumulated information and its diversity soon will probably lead to qualitatively new knowledge level with deep understanding of phenotype-associated strategy for managing OA patients.

REFERENCES:

[1] Wallace IJ, Worthington S, Felson DT, et al. Knee osteoarthritis has doubled in prevalence since the mid-20th century. Proc Natl Acad Sci USA. 2017 Aug 29;114(35): 9332-9336. doi: 10.1073/pnas.1703856114 Epub 2017 Aug 14.

[2] Deveza LA, Nelson AE, Loeser RF. Phenotypes of osteoarthritis: current state and future implications. Clin Exp Rheumatol 37 Suppl 2019;120(5):64-72.

[3] Van Spil WE, Bierma-Zeinstra SMA, Deveza LA, et al. A consensus-based framework for conducting and reporting osteoarthritis phenotype research. Arthritis Res Ther. 2020;22(1):54. doi:10.1186/s13075-020-2143-0

Disclosure of Interests: None declared.

DOI: 10.1136/annrheumdis-2021-eular.36

\section{AB0583 1 FRAILTY IN THE PATIENTS WITH OSTEOARTHRITIS OF THE KNEE WAS NOT CAUSED BY SARCOPENIA}

K. Inui ${ }^{1,2}$, K. Mandai ${ }^{1}$, T. Ikawa ${ }^{1}$, Y. Minami ${ }^{1}$, K. Ueno ${ }^{1}$, H. Ohashi ${ }^{1} .{ }^{1}$ Osaka Saiseikai Nakatsu Hospital, Orthopaedic Surgery, Osaka, Japan; ${ }^{2}$ Osaka City University Graduate School of Medicine, Orthopaedic Surgery, Osaka, Japan

Background: Osteoarthritis of the knee (knee OA) decreases mobility of the elderly, which function could be significantly improved with artificial joint replacement in many cases. Successful results of the surgery depend on several factors including preoperative muscle strength of lower limbs.

Objectives: We assessed morbidity and skeletal muscle mass and strength in patients with knee OA immediately before undergoing arthroplasty and investigated the relationship between impairment of mobility and skeletal muscle function.

Methods: All patients scheduled to undergo knee arthroplasty at our hospital after July 2020 were assessed for basic attributes, clinical assessment, blood tests, radiography, whole-body mode DXA, knee muscle strength by dynamometer with written consent (UMIN ID: 000040940). And Japanese Cardiovascular Health Study criteria for frailty, and sarcopenia by Asian Working Group for Sarcopenia 2019 criteria were evaluated.

Results: Among 46 patients (40 women, mean age 75.4 years) the overall distribution in frailty is no: $15.9 \%$, pre-frailty: $56.8 \%$, and frailty: $27.3 \%$. That in sarcopenia is no: $91.3 \%$, yes: $2.2 \%$, and severe: $4.3 \%$. Ninety-one $\%$ of the patients with frailty did not suffer from sarcopenia. Between the patients with frailty and those without frailty there was a significant difference in walking speed $(0.71 \pm 0.29 \mathrm{~m} /$ sec, $1.12 \pm 0.29 \mathrm{~m} / \mathrm{sec} ; \mathrm{p}=0.004$ adjusted by age and sex). Meanwhile, between those 2 groups of patients no significant differences were observed in skeletal muscle mass $\left(6.40 \pm 0.87 \mathrm{~kg} / \mathrm{m}^{2}, 6.59 \pm 1.09 \mathrm{~kg} / \mathrm{m}^{2} ; \mathrm{p}=0.35\right)$ and knee extension power $(120.4 \pm 37.4 \mathrm{~N}, 143.7 \pm 67.9 \mathrm{~N} ; \mathrm{p}=0.88)$ adjusted by age and sex. Together with these results, decrease in lower limb motor functions of the patients with knee OA was not caused by sarcopenia. In other words, improvement of mobility in the patients with knee OA could be expected by surgical intervention because of pain relief and ROM improvement.

Conclusion: In the patients with knee OA immediately before arthroplasty, frailty was not caused by sarcopenia.

Disclosure of Interests: None declared.

DOI: 10.1136/annrheumdis-2021-eular.416

\section{AB0584 \\ THE QUALITY OF REPORTING IN RANDOMIZED CONTROLLED TRIALS OF HOME BASED REHABILITATION FOR KNEE OSTEOARTHRITIS: UTILIZING PEDRO SCORE AND CONSORT CRITERIA}

M. Meran ${ }^{1,2}$, B. Unver ${ }^{1}$, E. Çağlar ${ }^{3} .{ }^{1}$ Dokuz Eylul University, School of Physical Therapy and Rehabilitation, Izmir, Turkey; ${ }^{2}$ Istanbul Beykoz University, School of Physical Therapy and Rehabilitation, Istanbul, Turkey; ${ }^{3}$ Istanbul Gelisim University, Faculty of Health Science/ Physical Therapy and Rehabilitation, Istanbul, Turkey
Background: Osteoarthritis of the knee (KOA) is a very common rheumatic disease, and its global burden is gradually increasing (1). The benefits of exercise in patients with KOA are supported by high-level evidence and take their place in primary care therapy (2). Today, coronavirus disease 2019 has developed as a pandemic all over the world, creating difficulties in healthcare and highlighting home-based rehabilitation ( $\mathrm{HBR}$ ) (3). Randomized controlled trials (RCTs) are considered the gold standard for evaluating the effects of clinical interventions but poorly reported results can have negative consequences. The Physiotherapy Evidence Database (PEDro) evaluates the methodological quality of RCTs (4). The CONSORT (Consolidated Standards of Reporting Trials) statement has been developed to improve the reporting quality of RCTs (5). There are no studies examining the quality of RCTs related to HBR in patients with KOA.

Objectives: The aim of this study was to assess the reporting quality of HBR trials for KOA, and explore the factors associated with the reporting.

Methods: Two independent researchers investigated HBR RCTs in patients with KOA published between 1999 and 2020 were sourced from PubMed, the Cochrane Reviews and Web of Science. Each researcher evaluated the methodological quality of the included studies using the PEDro scoring and reporting aspects using 9 items from CONSORT. The relationship between adherence to the CONSORT criteria and the PEDro score were evaluated.

Results: Twenty-five RCTs met our eligibility criteria. The mean PEDro score of studies is $5.76 \pm 1.48$. Only one study found high quality (PEDro score: $\geq 9$ ). The PEDro scores were: randomization type (96\%, 24/25) and baseline comparability $(92 \%, 23 / 25)$; all studies described group comparisons and variablity measures. In contrast, concealed allocation (18\%, $7 / 25)$, blinding of participants (16\%, 4/25) and therapists $(0 \%)$ were not included in most studies. The CONSORT criteria were: flow diagram $(92 \%, 23 / 25)$, sample size, subgroup analysis and sources of funding $(56 \%, 11 / 25$ for all three), while the majority of studies the trial registration number $(16 \%, 4 / 25)$ was not available. A high level of correlation was found between meeting the CONSORT criteria and PEDro scores $(r=0.820, p<0.001)$. Conclusion: The majority of RCTs based on HBR for KOA are low-to-modarate quality studies based on the PEDro score. Adherence to the CONSORT criteria is linked to high quality scores. If the studies are planned and written in accordance with the CONSORT criteria, we think that better quality studies will emerge. REFERENCES:

[1] Safiri S, Kolahi AA, Smith E, Hill C, Bettampadi D, Mansournia MA, et al. Global, regional and national burden of osteoarthritis 1990-2017: a systematic analysis of the Global Burden of Disease Study 2017. Ann Rheum Dis. 2020;79(6):819-28.

[2] Skou ST, Pedersen BK, Abbott JH, Patterson B, Barton C. Physical Activity and Exercise Therapy Benefit More Than Just Symptoms and Impairments in People With Hip and Knee Osteoarthritis. J Orthop Sport Phys. 2018;48(6):439-47.

[3] Karasavvidis T, Hirschmann MT, Kort NP, Terzidis I, Totlis T. Home-based management of knee osteoarthritis during COVID-19 pandemic: literature review and evidence-based recommendations. J Exp Orthop. 2020;7(1):52.

[4] Sherrington C, Herbert RD, Maher CG, Moseley AM. PEDro. A database of randomized trials and systematic reviews in physiotherapy. Man Ther 2000;5(4):223-6

[5] Moher D, Hopewell S, Schulz KF, Montori V, Gøtzsche PC, Devereaux PJ, et al. CONSORT 2010 explanation and elaboration: updated guidelines for reporting parallel group randomised trials. Int J Surg. 2012;10(1):28-55.

Disclosure of Interests: None declared.

DOI: 10.1136/annrheumdis-2021-eular.476

\section{AB0585 COMPARISON OF THE EFFECTIVENESS OF HYALURONIC ACID PREPARATIONS WITH DIFFERENT MOLECULAR WEIGHTS AND IN COMBINATION WITH CHONDROITIN SULFATE DEPENDING ON THE STAGE OF OSTEOARTHRITIS OF THE KNEE JOINT}

V. Bialik ${ }^{1}$, M. Makarov ${ }^{1}$, E. Bialik ${ }^{1}$, S. Makarov ${ }^{1}$, V. Nesterenko ${ }^{1}$,

M. Nurmukhametov ${ }^{1}{ }^{1}$ V.A. Nasonova Research Institute of Rheumatology,

Rheumoorthopedic and Rehabilitation, Moscow, Russian Federation

Background: intra-articular (IA) injections of hyaluronic acid (HA) preparations are one of conservative treatment of the knee osteoarthritis (OA). However, the results of this treatment are inconsistent.

Objectives: to evaluate the effectiveness of HA preparations with different molecular weights and in combination with chondroitin sulfate (HS) for IA injections in the treatment of patients with stage I-III knee OA.

Methods: IA HA injections were performed 160 patients with primary and post-traumatic knee OA of the I-III stages at the department of rheumoorthopaedic and rehabilitation, V. A. Nasonova Research Institute of Rheumatology for the period from September 2017 to June 2019. Patients were divided into 4 groups. Group 1 consisted of 80 patients treated with low molecular weight (LMW) HA group 2 - 20 patients treated with medium molecular weight (MMW) HA, group 3 - 30 patients treated with high molecular weight (HMW) HA, and group $4-30$ 